\title{
O Mfûmu e o Lûmbu: Uma nova perspectiva angolana sobre liderança
}

\section{The Mfûmu and the Lûmbu: A new Angolan perspective on leadership}

\author{
$1 \quad$ E-mail: $\quad$ benjamim $@$,dzzzz.info; \\ DZZZZ Consulting Services
}

Benjamim Adérito da Silva Mosquito M'Bakassy ${ }^{1}$

\begin{abstract}
Resumo
As organizações angolanas são normalmente conotadas com processos desatualizados de gestão e desenvolvimento de liderança o que oferece uma oportunidade à academia de assumir o papel de motor na transferência de conhecimento teórico para a sociedade. Neste ensaio apresentaremos teorias de liderança e autoridade e serão expostos possíveis argumentos para atribuir maior protagonismo a uma nova perspetiva angolana para o desenvolvimento de administradores e lideres. Palavras-chave: Liderança; Autoridade; Mfûmu; Lûmbu; Angola; Kôngo.

Abstract

Angolan organizations are often portrayed as enablers of archaic management and leadership development processes. This may offer an opportunity for academics to become the main agents in the transfer of theoretical knowledge to society. This essay presents leadership theories and possible arguments for the increasing demand for a new Angolan perspective for the development of managers and leaders.

Keywords: Leadership; Authority; Mfûmu; Lûmbu; Angola; Kôngo.
\end{abstract}

\section{Introdução}

Este ensaio começa por refletir (a) sobre o que é autoridade segundo Weber e (b) o que é liderança. Em seguida (c) é apresentada uma perspetiva do estudo sobre o Mfûmu e Lûmbu de Batsîkama (2011) e (d) possíveis implicações para a uma nova perspetiva angolana sobre liderança. Este ensaio (e) é uma breve reflexão sobre liderança, autoridade e de uma nova perspetiva angolana com (f) perfil qualitativo.

Problemas: (a) há um número reduzido de pesquisa sobre administração em Angola; (b) do ponto de vista multidisciplinar a pesquisa publicada sobre o Lûmbu por Batsîkama (2011) pode fornecer uma nova linha de estudo da liderança de uma perspetiva particularmente angolana; (c) o conhecimento teórico sobre liderança e (d) autoridade pode ser um fator chave ao desenvolvimento de líderes em Angola.

Problemática: a adoção de modelos de desenvolvimento de liderança está diretamente ligada com a relação entre o conhecimento que os atuais acadêmicos angolanos produzem, adquirem e transferem da academia para mercado.

Objetivos: (1) apresentar a dimensão acadêmica e multidisciplinar da liderança; (2) avaliar a possível importância de uma nova perspetiva angolana. 
Pressupostos: (a) é possível desenvolver uma nova perspetiva teórica angolana sobre liderança; (b) existe uma relação entre o conhecimento gerado na academia e os modelos de administração e desenvolvimento de liderança implementados em um determinado mercado.

Hipóteses de trabalho: (1) a sociedade e o mercado angolano está carente de modelos contemporâneos de gestão baseados em melhores práticas; (2) as melhores práticas de gestão e desenvolvimento de liderança têm uma forte ligação com o conhecimento desenvolvido na academia que desagua no mercado (3) os gestores angolanos estão abertos a novas metodologias de gestão e desenvolvimento de liderança; (4) sem o desenvolvimento de uma perspetiva angolana será difícil estabelecer uma escola de administração e liderança que torne fluida a aplicação de modelos de gestão atuais ao contexto angolano tendo em conta a sua especificidade socioculturais.

Justificativa: Este ensaio é importante porque faz a ponte entre o valor da liderança moderna como consequência do conhecimento teórico gerado e as necessidades que esse mesmo conhecimento pode suprir num contexto geográfico e cultural específico. É relevante perceber de que forma uma nova perspetiva angolana pode contribuir para o desenvolvimento e transferência de melhores práticas de desenvolvimento de liderança. Será útil, não apenas para acadêmicos mas também gestores e líderes afetos a Angola, perceber que existe um corpo de conhecimento sobre a arte de liderar mas que é fundamental investir na pesquisa acadêmica com uma delimitação geográfica especifica para que não se tente aplicar de forma arbitrária melhores práticas que podem ser pertinentes em uma outra geografia mas que devido ao contexto histórico, cultural e de desenvolvimento presente podem não ser adequadas a Angola.

Trata-se de uma abordagem bibliográfica e qualitativa da importância do conhecimento enquanto guardião e gerador de melhorias na área da administração e desenvolvimento de liderança. No ensaio é apresentada uma perspetiva angolana do conhecimento teórico sobre liderança e possíveis motivos para ser atribuída maior importância à construção de uma escola angolana de conhecimento sobre o tema.

\section{Revisão da Literatura}

\section{Weber e Autoridade}

Max Weber abordou o tema do poder e autoridade como central à dinâmica social e cultural (McGrath \& Bates, 2013). Weber identificou três fontes de autoridade ou poder que repartiu em três categorias, nomeadamente autoridade carismática, autoridade tradicional e autoridade burocrática (McGrath \& Bates, 2013). Recentemente o acadêmico português, Professor Doutor Miguel Pereira Lopes que se referia a Weber num contexto do estudo da liderança e que fazia do modelo de tripartido de autoridade um excelente ponto de partida para caracterizar a liderança na lusofonia. Em poucas palavras e fazendo referência ao exemplo do Marquês de Pombal, Lopes (2014) explica de forma clara a forma como o modelo tripartido de Weber pode ser usado para caracterizar não apenas autoridade ou poder mas estilos de liderança assim como a capacidade que alguns líderes possuem para exercer a sua função. Segundo Lopes (2014), o Marquês de Pombal era aquilo a que Weber definiria como um líder carismático, alguém cuja capacidade de atrair seguidores era uma consequência direta da sua personalidade e perceção de seus súbditos sobre a sua capacidade de produzir resultados acima daquilo que poderia ser esperado de um ser humano comum. Já a autoridade tradicional, segundo Weber, é caracterizada pela hereditariedade de 
autoridade ou poder que pode ser exercido por indivíduos, famílias, elites ou grupos que transmitem essa mesma autoridade ou poder de geração em geração (McGrath \& Bates, 2013). Segundo Lopes (2014), um dos maiores segredos do Marquês de Pombal foi a capacidade de perceber a necessidade de uma terceira fonte de autoridade a que Weber denominou de autoridade burocrática. A autoridade burocrática caracteriza-se por ser baseada em responsabilidades ligadas a um certo cargo formal. O mais usual é que as pessoas que exerçam um certo cargo o façam tendo sido nomeadas e educadas para exercerem esse cargo de forma tecnicamente competente. Segundo Lopes (2014) foi a esta autoridade que o Marquês de Pombal recorreu para a reconstrução de Lisboa depois do terramoto na forma de especialistas em urbanismo. Um outro exemplo que pode ser usado para exemplificar o modelo tripartido de autoridade de Weber de forma transparente é a Igreja Católica que possui em Cristo a autoridade carismática, nos sacerdotes a autoridade tradicional e no Papa a autoridade burocrática.

O modelo tripartido de Weber permite perceber e analisar líderes de forma clara de que tipo de autoridade estamos a falar. No contexto angolano e de uma perspetiva angolana permite olhar para as lideranças e categorizá-las de forma simples e sistemática, algo que muitas vezes é feito de forma politizada quando o podia ser com o recurso a modelos um pouco mais metodológicos.

\section{Adair e o desenvolvimento de líderes}

O interesse pela literatura relacionada com o desenvolvimento de liderança é algo que acompanha a história da humanidade mas que teve um crescimento exponencial com o aumento dos direitos fundamentais do cidadão, a expansão do sistema de ensino, a institucionalização do capitalismo e adoção de uma economia de mercado à escala global.

O desenvolvimento social fez crescer o número de responsabilidades da sociedade civil assim como o número de líderes envolvidos com os processos de desenvolvimento. Do ponto de vista econômico o maior número de empresas e empreendedores fez crescer o número de gestores e diretores responsáveis por organizações com um número cada vez maior de trabalhadores, processos e operações cada vez mais complexas, e uma necessidade de gestão de conhecimento como nunca antes havia sido demonstrada na história da política económica.

Até ao final do século XIX a literatura em geral e a literatura relacionada com liderança em particular estava apenas acessível a uma elite. É com o desenvolvimento de uma sociedade consciente do valor da educação e crescimento do número de leitores que temas como a liderança entram para o espectro de interesses populares. Primeiramente através de autores com uma abordagem em que a religião e os exemplos religiosos assumiam lugar de destaque, posteriormente por autores com perspetivas agnósticas, e mais recentemente a representação de liderança no contesto académico. Considerado o primeiro professor de liderança, John Adair transformou a liderança em conhecimento sistemático nas suas correntes teóricas e pedagógicas assumindo um papel fundamental no processo de adoção do ensino de liderança e desmantelando dogmas arcaicos sobre as características de um líder como a capacidade de se educar alguém para assumir posições de liderança.

Com o número cada vez maior de indivíduos com possibilidades de construírem os seus próprios negócios e assumirem posições com cada vez maior responsabilidade em organizações cada vez maiores e mais influentes, o interesse pelo tema tende a crescer. Uma das maiores motivações para o crescimento 
do tema é a consciência cada vez maior pela necessidade do desenvolvimento do carácter, competências psicológicas, cognitivas, e espirituais do indivíduo.

Contudo foi Adair (2005) que trouxe metodologia para a análise do processo de desenvolvimento de liderança e quebrou preconceitos relacionados com fatores quase que místicos relacionados com lideres e o seu desenvolvimento.

O seu conceito sobre a divisão e relação entre indivíduo, equipa e tarefa oferece uma perspetiva simples e eficaz sobre a gestão de processos por parte de um líder (Adair, 2005).

O que John Adair descreve é uma relação interdependente na qual as necessidades do indivíduo, equipa e tarefa devem ser satisfeitas de forma harmoniosa. Enquanto líderes precisamos gerir pessoas, pessoas estas que formam equipas de trabalho responsáveis pelo desempenho de uma determinada tarefa de forma eficiente (Adair, 2005).

Talvez a mais importante lição de Adair (2005) seja a mensagem de que líderes podem ser cultivados de forma prática. Para Adair (2005) traços como carisma são extremamente importantes mas devem estar ao serviço de uma predisposição para o cultivo de líderes seguindo a seguinte fórmula:

1. Planeamento estratégico: deve haver um plano de desenvolvimento de talento e recursos humanos

2. Seleção: devem ser identificados indivíduos com potencial para assumir funções de liderança no futuro com perspetivas de longo prazo (5-10 anos)

3. Formação: devem ser criadas sessões de formação em que indivíduos têm oportunidades de desenvolver as suas competências teóricas/conceptuais, técnicas e práticas

4. Experiência: devem ser criadas oportunidades para o exercício de funções de liderança

5. Mentores: gestores, diretores e administradores devem servir de mentores no processo de desenvolvimento dos membros das suas equipas

6. Cultura organizacional de desenvolvimento de liderança: todas as organizações devem promover um espirito de iniciativa e pro-atividade

7. Líder como exemplo e motor do desenvolvimento de liderança: no final do dia o desenvolvimento de lideranças futuras é responsabilidade do líder

\section{Mfûmu e Lûmbu. Uma nova perspectiva sobre autoridade e desenvolvimento de liderança em Angola}

No seu livro "Democracia no Reino do Kôngo", que é a publicação de parte da sua pesquisa acadêmica, Batsîkama (2011) articula de forma brilhante o papel da autoridade ou Mfûmu na formação da liderança em Angola.

\footnotetext{
“" (...) poder nasceu no "seio de várias" famílias da mesma origem (vumu): o mais velho que inicialmente assume a liderança para estabelecer a harmonia e a concordância entre vários ganhará outro sentido: aquele que é reconhecido pelas leis dos ancestrais-fundadores como líder de inúmeros "grupos de famílias". Aqui nasce a investidura. Desde então, $m f$ ûmu passa a ser uma autoridade investida: "kimfûmu mambu ma kya ñtûmbwa" (a autoridade é uma questão de investidura)."
} 
É particularmente interessante perceber que as estruturas formais de desenvolvimento de liderança estão presentes e podem ser pesquisadas de forma metodológica para que se possa perceber o contexto no qual as autoridades atuais exercem as suas funções. Por se tratar de um ensaio iremos realçar de forma breve a estrutura da pesquisa de Batsîkama (2011) e faremos recurso a uma figura sobre o conteúdo da obra de Batsîkama (2011) para fazermos perceber a riqueza do seu contributo ao estudo da liderança.Assim sendo, a estrutura da pesquisa assenta na linguística comparativa e no Lûmbu ou Conselho Supremo do país a principal autoridade que se divide nas suas diversas funções.

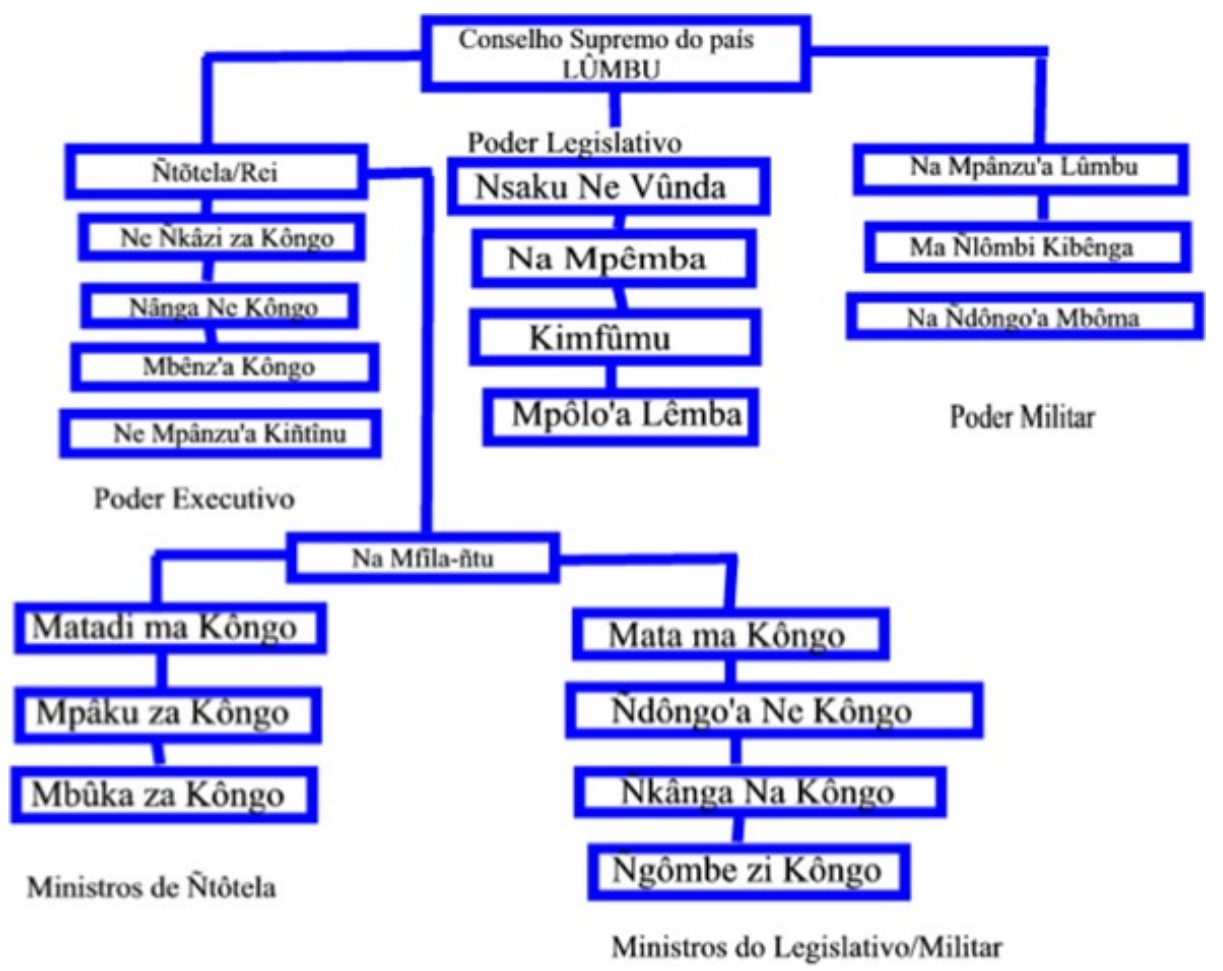

Figura 1. Esquema geral da pesquisa de Batsîkama (2011, p. 55)

No final do livro, Batsîkama (2011) define o Lûmbu da seguinte forma:

O "Lûmbu" é considerado hoje como "tribunal tradicional" e, como mostramos neste texto, trata-se aqui de um pequeno legado de uma grande instituição (Lûmbu) que no passado assegurava, no Kôngo:

(1) O Diálogo permanente de 12 representantes de 144 tribos que formavam a União/Kôngo na base da "Irmandade institucionalizada/Constitucional";

(2) A Paz, não como dádiva, mas sim como um "património por construir" com a participação e vontade aberta de todas forças sociais constituintes.

(3) A União: as contradições são importantes (bana batele; bana basekole) para fortalecer uma União plural (busânga, bungûdi: união faz a força) que valoriza as diferenças.

É por essa razão que a pesquisa de Batsîkama (2011) poderá ser fundamental ao estudo da liderança em Angola.

\section{Considerações finais}

Por se tratar de um ensaio tomamos a liberdade de terminar citando aquele que é provavelmente o exponente máximo da liderança empresarial na lusofonia, o CEO do Abbey, António Horta-Osório, mais 
precisamente o seu prefácio no livro de Filipe Fernandes (2007) com o sugestivo título "Organizem-se! A gestão segundo Pessoa".

\footnotetext{
"O objetivo de um gestor não é só liderar e fazer coisas através das pessoas, mas também deixar escola, de forma a que amanhã possa ser substituído sem qualquer problema. Os grandes lideres criam equipas, que um dia os podem dispensar, sem prejuízo da performance"Fernandes (2007, p.16)
}

Este ensaio é um exercício de reflexão tendo em conta fontes que podem ser consideradas fundamentais para um entendimento da liderança de uma perspetiva angolana. Max Weber transformou a sociologia, John Adair foi o primeiro professor de liderança e Patrício Batsîkama tem vindo a produzir pesquisa que poderá ser essencial ao entendimento da dimensão cultural nos sistemas de autoridade e liderança de numa nova perspetiva angolana. Sendo que o estudo da liderança é o produto de cruzamentos multidisciplinares este ensaio não é mais que uma reflexão sobre autores e teorias fundamentais para que administradores e lideres possam desenvolver perspetivas sobre o que é liderança e como no futuro pode ser abordada de forma metodológica mas com cada vez maior ênfase num olhar angolano sobre o futuro da liderança em Angola.

\section{Referências}

Adair, J. E. (2005). How to Grow Leaders: The Seven Key Principles of Effective Leadership Development. Sterling: Kogan Page Publishers.

Batsîkama, P. (2011). Lûmbu: A democracia no Reino do Kôngo. Luanda, Angola: MediaPress.

Fernandes, F. S. (2007). Organizem-se! A gestão segundo Fernando Pessoa. Oficina do Livro.

Lopes, M. P. (2014). Portugal tem um défice de gestão muito grande e prefere os líderes carismáticos. Obtido de http://portaldalideranca.sapo.pt/arquivo/destaque/miguel-pereira-lopes-portugal-temum-defice-de-gestao-muito-grande-e-prefere-os-lideres-carismaticos

McGrath, J., \& Bates, B. (2013). The Little Book of Big Management Theories: ... and how to use them. Edinburgh Gate: Pearson Education. 